\title{
DISPOSICIONES SOBRE JUDÍOS EN LOS FUEROS DE CASTILLA Y LEÓN
}

\author{
Pilar León Tello
}

No se ha determinado aún, de una manera definitiva, el panorama jurídico de los fueros, a pesar de que hay ya muchas ediciones críticas de los mismos. Los primitivos fueros latinos se han perdido casi en su totalidad y sólo los conocemos a través de confirmaciones posteriores que en muchos casos nos han llegado en copias bastante defectuosas.

Las cartas pueblas, de índole rural, establecían las relaciones vecinales de los que acudían a los lugares de asentamiento; en tanto que los fueros se concedian en zonas ya repobladas. Sus textos varían mucho en extensión y en contenido; como fase previa regían las prescripciones de carácter consuetudinario, y después de concedido el privilegio foral, se solían incorporar otras ordenanzas en sucesivas etapas, dictadas por las autoridades locales.

Hay fueros breves y extensos, latinos y romanceados, empezando éstos a aparecer hacia la segunda mitad del siglo XIII; no todos eran reales, sino que los podían otorgar los señores, eclesiásticos o laicos, y muchas veces los municipios en avenencia con los monarcas.

Los primeros fueros locales se remontan al siglo IX, pero los judíos no aparecen en los fueros hasta el de Castrojeriz que fue dado en el año 974 por el conde de Castilla, García Fernández; 
en la cláusula referente a homicidios se establece que se pagaría por la muerte de un judio la misma cantidad que si se tratase de un cristiano.

En el fuero de León, en el caso de que algủn vecino quisiera vender su casa, debía de ser apreciada por dos cristianos y dos judios, lo que da idea de la buena opinión que se tenía de éstos en esa época'.

En los fueros, por lo general, se convocaba a todos, cristianos, moros y judíos, para que acudiesen a poblar las villas.

Siguiendo en lo posible el hilo cronológico, encontramos en el de Briviesca, que Alfonso VII extiende el fuero a cualquier judío que fuese a habitar en la ciudad. En el de Alcalá, otorgado por los arzobispos de Toledo, se deja en libertad a los judíos para que residan en la ciudad o se vayan a la buena ventura adonde quisieren. El de Abia de las Torres se concede a francos, castellanos, judíos y moros, sin distinción.

En cambio sí hay una diferencia peyorativa en el fuero de Catalifa al establecer que los moradores que hicieren tienda en su heredad, podrian tenerla siempre, pero las que construyeran judíos o moros, serían propiedad del palacio.

En Lerma todos los vecinos, infanzones, judios, villanos o del alfoz, pagarían la misma infurción que determinaba el fuero, y la misma caloña por sus delitos; todos tenían que dar cada año una ofrenda de 5 panes, dos cuarterones de vino, dos dineros en carne y dos medidas de cebada. También en Zorita de los Canes disfrutaban los judíos de los mismos derechos y desventajas que los otros pobladores cristianos.

En el privilegio de Molina a todos los vecinos, caballeros, clérigos y judíos, se les concedía que pudieran tomar sendos cahices de sal anualmente, por un mencal. En este fuero y en el de Lara aparecen también los tornadizos o conversos.

Por último en el fuero de Cuenca y sus derivados como Alcaraz, Alarcón, Alcázar, Úbeda, Baeza y Sepúlveda, se formula la misma franqueza de población a cristianos, moros y judíos,

1 Véase al final de este articulo, las ediciones consultadas. Fuero de CasIrojeriz, 16, 19 y 21, pp. 120-121. Fuero de León, núm. 25, p. 20. 
así libres como siervos, eximiéndoles de responder por enemistad, por deuda, fianza, herencia, mayordomía o merindad, ni por ningún mal que hubieran hecho antes de que cada una de esas ciudades fueran tomadas. En el de Sepúlveda, sin embargo, se prohíbe a los judíos que tengan bienes raíces propios.

Una disposición del fuero de Salamanca dispone que los judíos fuesen "encotados», ellos y sus heredades, como si fuesen vecinos de Salamanca ${ }^{2}$.

Los judios se consideraban propiedad de los reyes quienes hacían respetar sus derechos a residir en la península a cambio de unas contribuciones directas que pagaban a la corona; los monarcas los consideraban como su «cosa propia e quita». En el Libro de los fueros de Castilla se sienta el principio de que los judíos son del rey; «maguer que sean so poder de ricos omnes o con sus cavalleros o con otros omnes o so poder de monesterios, todos deven ser del rey en su goarda o para su servyçio».

En los fueros locales derivados del de Cuenca al tratar de homicidios, se inserta la idea de que los judios pertenecían al rey y a su tesoro; el fuero de Béjar aclara: «ca los iudios siervos son del rey e acomendados por la bolsa del rey propria».

En los fueros leoneses están los judíos bajo el poder del rey y del concejo, como figura en el de Ledesma y en el de Salamanca: «E metelos el rey en manos del conceyo de Salamanca, que los ampare con derecho. $\mathbf{E}$ deuen dar los iodios al re cada Nathal, XV marauedís en rienda; e que los den per manos de los alcaldes e de las iusticias $)^{3}$.

${ }^{2}$ Fuero de Briviesca (núm. 15), p. 136. Fuero de Alcalá, \& 171, p. 305. Fuero de Abia de las Torres, p. 234. Fuero de Catalifa, p. 532. Fuero de Lerma, 3, p. 153. Fuero de Zorita de los Canes, p. 419. Fuero de Lara, 31, p. 141. Fuero de Cuenca, capitulo I, ley 10. Fuero de Alcaraz, título 12, p. 88. Fuero de Alarcón, título 1, 10, p. 88. Fuero de Úbeda, titulo 2, p. 256. Fuero de Sepuilveda, título 12, pp. 64-65. Fuero de Salamanca, \& 341, p. 201.

${ }^{3}$ Fuero de Castilla, \& 107. Fuero de Cuenca, capitulo 29, 7-8. Fuero de Úbeda, tit. 53, p. 363. Fuero de Béjar, \& 892, p. 122. Fuero de Ledesma, \& 399, p. 286. Fuero de Salamanca, \& 341, p. 201. 


\section{PRINCIPALES TEMAS TRATADOS EN LOS FUEROS, EN RELACIÓN CON LOS JUDÍOS}

\section{Alcaldes, jueces $y$ albedinos}

Desde el siglo xi se emplean indistintamente los nombres de juez y alcalde, principalmente, en los fueros leoneses por influencia de los mozárabes que se habian asentado en esa zona.

En algunos fueros como el de Toledo, ciudad de amplia judería, eran los jueces cristianos los que intervenían en los juicios mixtos; tanto en éste como en el fuero de Escalona se prohibia que jueces judíos actuaran contra los fieles. En el de Ledesma, el alcalde que juzgara entre cristiano y judío, tenía que requerir la presencia de otro judío.

En los fueros de Cuenca, Zorita, Úbeda y otros derivados del conquense, para las causas mixtas se nombraba dos alcaldes vecinos, uno de cada raza; y si a alguno de los litigantes no parecía bien la sentencia, podían apelar en última instancia a cuatro alcaldes, dos cristianos y dos judios.

El fuero de Soria establece que sean seis hombres buenos y discretos, dados por los alcaldes, los que juzgasen todos los pleitos mixtos.

En Sahagún, estos pleitos se juzgarian por los alcaldes de la villa, pero todas las demandas promovidas entre cristianos y judios, debían pasar por dos pruebas, por cada una de las partes. El abad, que era el señor de ese territorio, tenía facultad para poner sobre los judios un albedi que solucionara sus problemas; podian ser juzgados también por los adelantados que nombrasen los rabíes de Burgos, incluso tenían derecho de alzada a estos rabies.

En el fuero de Sepúlveda no aparece un juez especial de judíos, debido probablemente al acuerdo tomado en las cortes de Valladolid de 1293, que había prohibido la existencia de jueces apartados. Todos los judíos de Sepúlveda tenían que pagar a los jueces, precisamente porque no les tenian puertas para sus juicios ${ }^{4}$.

${ }^{4}$ Fuero de Toledo, pp. 473-483. Fuero de Escalona, 12, p. 465. Fuero de 
Se incluyen a moros y judios en la prohibición de sacar armas de las villas, tanto si son de fuste como de hierro, bajo multa de 20 mrs. y exención de pagar caloña al que se las quitare a la fuerza ${ }^{5}$.

\section{Baños}

Todos los fueros que insertan esta rúbrica señalan los mismos días para el uso del baño de la villa: a los hombres se les asignan los martes, jueves y sábados; a las mujeres, los lunes y miércoles, y a los judios, viernes y domingo.

Si un cristiano entraba al baño en el día que tocaba a los judios o viceversa, podían herir y hasta matar al intruso con completa impunidad.

Según el fuero de Alcaraz, tanto el hombre como la mujer no tenian que pagar por baño más que una meaja; en Zorita dice un solo óbolo. El señor del baño tenía que proporcionar agua y otras cosas necesarias.

Las Partidas recogen también la separación de los judios en los baños ${ }^{6}$.

Ledesma, \& 397, p. 286. Fuero de Cuenca, cap. 21, ley 9. Fuero de Úbeda, titulo 53, p. 360. Fuero de Zorita, rúbrica 577, p. 270. Fuero de Soria, cap. 10, ley 108. Fuero de Sahagún, leyes 39, 40 y 42, p. 234. Fuero de Sepúlveda, tit. 72 , p. 91.

5uero de Cuenca, tít. 29, ley 29. Fuero de Zorita de los Canes, tit. 603, p. 278 . Fuero de Úbeda, tít. 53, p. 363.

- Fuero de Cuenca, cap. 2, ley 32. Fuero de Béjar, tít. 67,69 y 70, p. 19. Fueros de Alcaraz, 32 y 33, pp. 116 y 117 . Fuero de Alarcón, tít. 53 y 55 , pp. 116 y 117. Fuero de Zorita, 43 y 45, pp. 68 y 69. Fuero de Sepuilveda, tit. 111, p. 103. Fuero de Úbeda, tit. 9, ley 2, p. 264. Partidas, VII, $24,8$. 


\section{Denuestos}

Los insultos de palabra se castigaban en la legislación goda y están recogidos en Libro II, tít. $3^{\circ}$ del Fuero Juzgo. Se encuentran también en algunos fueros extremeños y entre los insultos dirigidos a otra persona y que se multaban con pena de $5 \mathrm{mrs}$., figuran el de cornudo, gafo, judío o traidor.

En el Libro de los fueros de Castilla se dispone que por ningún denuesto que dijere un judío a otro, debía dar querella al señor si no quisiere, ni tendría nada que pechar, pero más adelante lo castiga si el denuesto es probado y sabido, a pagar 20 sueldos; y 25 , al judío que dijere a una judía "puta provada" 0 «sabida».

En el fuero de Ledesma si un cristiano amenazaba a un judio y éste se sentía atemorizado, estaba obligado el cristiano a darle salva fe o tendría que pechar $6 \mathrm{mrs}$. cada día. El mismo fuero imponía la multa de 300 sólidos al que rompiere casa de judío o judía?

Ferias y mercaderes

Entre los mercaderes que acuden a las villas, se consideran en plano de igualdad a cristianos, judíos y moros, a los cuales no se les podía prender a no ser que tuvieran deudas o fuere fiador; el que los prendase indebidamente pagaría $20 \mathrm{mrs}$. al concejo, y al querelloso, los daños doblados. Casi sin variantes encontramos esta rúbrica en los fueros de Cuenca y sus derivados.

En la misma línea de equiparación, se incluyen a los que fueran a la feria o mercado anual; en la familia de los fueros conquenses se celebraban 8 dias antes de la Cinquesma o Pentecostés y ocho después de estas fiestas; estaban protegidos por el coto regio de mil mrs. y el pago del daño doblado a la victima.

El fuero de Sepúlveda era muy riguroso: el que matase a otro

7 Fuero de Coria, 183, p. 60. Fuero de Cáceres, 186, p. L. Libro de los Fueros de Castilla, \& 217 y 220 . Fuero de Ledesma, 388, pp. 284 y 394, p. 285. 
en estos días de ferias, sería enterrado vivo debajo de la víctima; al que produjese heridas, se le cortaría la mano; el que robase alguna cosa y no tuviera bienes para devolver, sería despeñado.

En Cáceres se fija la feria una vez al año entre los últimos 15 días de abril y los 15 primeros de mayo; se convoca a todos los que quisieren ir a esta feria o mercado anual, a los de León, Castilla, Aragón, Navarra y Portugal, de las tres religiones, aunque fuere enemigo o siervo. Los alcaldes, notarios y mayordomos, rondarian la feria dia y noche.

En algunos fueros se limitaba a los judios la venta de carne en determinadas épocas: no podian venderla, a no ser la de cabra, tres días antes y tres después de la Pascua mayor, de la Navidad y de Pentecostés, bajo la amenaza de que podía quitársela cualquiera sin sufrir daño. El concejo de Salamanca castiga al carnicero que vendiere carne judiega además de a pagar una multa de 5 mrs., a quemarle la carne; si alguno matase carne para los judíos en carnaval o en cuaresma, "tresquilenlo los alcaldes», añade el fuero salmantino.

El pescado no podían venderlo los judíos en viernes, pues pretendían acapararlo y aumentar su precio en el día que los cristianos lo necesitaban para cumplir con el precepto de la vigilia.

La pena que se impone a los contraventores, es de un maravedí para los alcaldes; la misma multa se imponia a los cristianos que compraran pescado para los judíos.

Los que vendiesen agraz antes de la vendimia, estarían obligados a pagar un maravedi al amutaçaf o almotacén.

Aparece en los fueros el oficio del corredor impuesto por el juez y los alcaldes; podían ser cristianos, judíos o moros y su misión era vender paños, bestias u otras cosas por la villa o por el mercado; debian prestar juramento de cumplir su oficio bien, y lealmente. A todo el que vendiere mercancías sin ser corredor, se las podían quitar sin pagar caloñas.

El fuero de Ledesma establece que para las compras que hiciere un judio en el mercado de valor de medio maravedí, y siempre que pudiera verificarlas con sol, no estaba obligado a dar otor $^{8}$.

${ }^{8}$ Fuero de Sepúlveda, tit. 22, p. 68 y tit. 238, p. 147. Fuero de Soria, \& 109 , 


\section{Herencias}

Prohíbe el fuero de Soria lo mismo a clérigos que a legos, que dejen herederos a judíos, moros o herejes, bajo sanción de perder todo lo que heredasen. También prohíbe que sean albaceas, «cabeçales», de cualquier manda, no sólo a los judíos y demás nombrados, sino también a los siervos, religiosos, menores de edad, a los mudos y sordos y a los alevosos y traidores. Estas cláusulas pasan al Fuero Real?.

\section{Homicidios}

En todos los fueros encontramos una o varias rúbricas referentes a muertes, heridas o contusiones inferidas a los judíos o producidas por ellos. El castigo que se imponía a los autores podía ser de tres clases: pena de muerte o corporal, pena pecuniaria, y la enemistad, que daba derecho a vengarse a los parientes de la víctima.

Si la acusación de homicidio no era muy segura, podía salvarse el acusado mediante testificaciones de vecinos, según los procedimientos establecidos en cada lugar.

En los fueros más antiguos se equiparaban los judíos a los cristianos, en cuanto al homicidio o heridas. En el de Castrojeriz, la cláusula correspondiente es muy tajante: «Et si homines de Castro matarent judeo, tantum pectent pro illo, quomodo pro christiano, et libores similiter hominem villarum». Los judíos de Castro no debían gozar, sin embargo, de la benevolencia de sus convecinos pues el fuero nos informa que al morir Sancho el Mayor, se sublevaron los hombres de Castro, mataron cuatro

p. 41 y \& 414, p. 160. Fuero de Cuenca, cap. 26, ley 25. Fuero de Béjar, \& 533, p. 79. Fuero de Alcaraz, 29, p. 301. Fuero de Alarcón, tít. 385, p. 301. Fuero de Zorita, tit. 345, p. 183. Fuero de Úbeda, tit. 34, p. 328. Fuero de Ledesma, \& 391, p. 285. Fuero de Usagre, p. 145. Fuero de Cáceres, tít. 408, p. CXIV.

${ }^{9}$ Fuero de Soria, \& 302 y 329, pp. 109 y 119. Fuero Real, libro III, tít. V, 7. 
sayones del palacio del rey en el Mercadillo, y sesenta judios; a los otros, los sacaron de sus casas y heredades e hicieron que poblasen Castrillo. A la muerte de Alfonso I el Batallador, casado con la reina doña Urraca, hubo nuevo levantamiento contra los judíos de Castrillo, y a unos los mataron, a otros los cautivaron y a todos les robaron sus bienes.

Otros fueros repiten la equiparación de las penas por homicidio: el de Astudillo, que es una redacción sistematizada del de Castrojeriz; el de Nájera, que estima la vida de un judío igual a la de un infanzón o escapulado; en el de Belorado sólo se alude a livores, así como el de Pampliega que condena al que se los hiciera a un judio, a recibir los livores doblados; el fuero de Alcalá añade a la cláusula de reciprocidad, que no quedasen enemigos, ni cristianos ni judíos. También en Salamanca, en la cuestión del homicidio todos los vecinos eran iguales.

Generalmente se establecía en cada fuero el castigo o la caloña que se imponía a los homicidas.

En León en la carta entre cristianos y judios que otorgó Alfonso VI en 1091, se determina que en caso de que un cristiano produjese llagas, heridas o la muerte a un judio, si no estaba bien claro el delito, se harian pesquisas por los mejores vecinos y si no pudieren obtener una información satisfactoria, se resolvería la cuestión a bastonazos entre los interesados o entre personas elegidas por ellos; si fuere vencido el judío o su bastonario, pagaría 50 sueldos al rey y 50 al querellante; si resultaba vencido el cristiano, entregaría al rey toda la caloña.

En el fuero de Toledo de 1101 concede el rey a los habitantes que paguen sólo un quinto de toda la caloña, menos de la muerte de judío o de moro; en el de 1118 se condena a todo homicida a morir apedreado, y los acusados por sospecha, se atendrian a las disposiciones del Fuero Juzgo.

En el fuero más antiguo de Zorita, el que matase a un judío sólo pagaría un ochavo del homicidio. En el de Ledesma por el contrario, sería condenado a muerte siempre que se pudiera comprobar; el que lisiare a un judio, pagaría 30 maravedís; y el que lo hiriese con el puño, o con fuste, o lo mesare o le restregase el rostro con carne de puerco, pagaría 20 maravedís. 
En el fuero de Cuenca y otros con él relacionados como el de Alcaraz, Alarcón, Zorita de los Canes, Ubeda y Béjar, la caloña que se fija por herida o muerte de judío, es de 500 sueldos al rey, y en caso de señorío, como ocurría en Sahagún, esta cantidad, se entregaría al abad; en acusación dudosa, se podían salvar con el testimonio de 12 vecinos o sólo con dos, según se tratara de muerte o de heridas. Las caloñas por homicidio nunca se pagaban a los judíos que se consideraban siervos del rey «et deputados a la su mesa" según dice el de Zorita.

En Briviesca por la muerte de un judío serían condenados al pago de 100 sólidos; en Escalona, de 300.

En los fueros de Coria, Cáceres y el de Usagre, al que hería o producia livores a un judio, lo multaban con 2 o 4 maravedís respectivamente.

El fuero de Alba de Tormes es poco equitativo en esta materia, pues si por muerte de un judío se imponía 20 maravedís como caloña, en el caso de que el judío fuere el agresor, le harían justicia del cuerpo y perderia todos sus bienes; si no lo podian coger, quedaría enemigo de los parientes de la víctima, los cuales podían vengarse impunemente; pero si tras la pesquisa efectuada por hombres buenos cristianos, no pudiera probarse el delito, los alcaldes le darian tregua y quedaria a salvo.

En el fuero de Sepúlveda se incluye también los delitos de sangre con los moros.

El cristiano que hiriese a un judio y se pudiera probar, pagaría un maravedi; y si lo mataba, 100 maravedís y quedaría por enemigo para siempre al «amor» del querelloso y de sus parientes. Era mucho más grave el castigo impuesto al judío: por herida a cristiano, se le impondría la multa de $10 \mathrm{mrs}$., pero si lo mataba, moriría por ello y perdería todos sus bienes.

Judíos y moros estaban equiparados en castigo: 10 maravedís por heridas y 100 maravedís por muerte, y si no tuvieran esta cantidad, serían despeñados.

El Libro de los Fueros de Castilla determina que tanto cristianos como judíos pecharían las caloñas según las heridas o livores que hubieran hecho: si mataba el judío a cristiano, pagaría 500 sueldos, y si a otro judío, sólo 300 sueldos. Las heridas de 
judio a judio tenian distintas valoraciones según se las produjera con el puño, de carrellada o con hierro, agravándose la multa si se producía la herida el sábado y del golpe saliera sangre ${ }^{10}$.

\section{Juicios}

Los judíos según los fueros de Coria y Cáceres no podían mantener en los juicios su voz ni la ajena, y si la llevaran, pagarían 4 mrs. a los alcaldes; en los de Salamanca y Ledesma se establece que eran libres de dar su representación para pleitear, «a barayar», a quien quisieren, y el juez debía llevarla a derecho.

En el fuero de Soria se prohibía la firma en ninguna clase de pleito, al menor de edad, al traidor, alevoso, al excomulgado mientras lo fuese, a judio y moro en pleitos entre cristianos, al hereje, siervo, hombre de orden religiosa renegado, al que dé hierbas por hacer mal, al hechicero, robador y a todo el que no tuviese de 50 mrs. para arriba.

En los fueros de Cuenca y homogéneos en las demandas entre cristianos y judíos no podian ser confirmantes sino vecinos, y por sus testimonios, todas las cosas serían creídas y manifestadas; las firmas entre cristianos y judios no debían responder a reto. Tanto cristianos como judíos si no querían firmar lo que vieren, pagarían doblada la demanda.

En los pleitos o contiendas casi siempre presentaba los testi-

${ }^{10}$ Fuero de Castrojeriz, 16, 19 y 21, pp. 120 y 121. Fuero de Astudillo, 13 , p. 238. Fuero de Nájera, p. 289. Fuero de Belorado, 16, p. 134. Fuero de Pampliega, 15, p. 182. Fuero de Alcald, \& 171, p. 305. Fuero de Salamanca, \& 341, p. 202. Carta entre cristianos y judios de León, p. 90. Fueros de Toledo, núm. 5 , p. 460 y núms. 25 y 27, p. 478. Fueros de Zorita, p. 419 y \& 606 y 607 , pp. 279 y 280 . Fuero de Ledesma, \& 395, p. 285. Fuero de Cuenca, cap. 29, ley 32. Fuero de Alarcón, 589 a 591, p. 569. Fuero de Alcaraz, 31, 32, p. 569. Fuero de Úbeda, tít. 53, p. 363. Fuero de Béjar, \& 890-892, p. 122. Fuero de Briviesca, 15, p. 136. Fuero de Coria, \& 389, p. 104. Fuero de Cáceres, 395, p. XCII. Fuero de Usagre, 403. Fuero de Alba de Tormes, \& 12, p. 297. Fuero de Sepúlveda, tit. 37 a 39, 42, 43, pp. 73-76. Libro de los Fueros de Castilla, \& 216, 217 y 220. 
gos el acusador, pero a veces podía aportarlos el demandante frente al que negaba su compromiso.

En Salamanca, Ledesma y otros, se establece en los fueros que el que tuviera que atestiguar en los juicios firmaría con dos cristianas y un judio o con dos de estos y un cristiano. En Sepúlveda podían ser también tres cristianos o tres judíos. En Alba de Tormes solo necesitaban la firma de un vecino de cada ley. Dispone el de Ledesma que por firma de judíos y cristianos no podía un judío ser preso ni su haber ni su cuerpo, siempre que dieren buenos fiadores de que no habían matado a nadie.

Los emplazamientos para las demandas entre cristianos y judíos, según los fueros de la familia conquense, debían efectuarse ante la puerta de la alcacería o de la alcazaba y no de la sinagoga; sin embargo el de Zorita y el de Alba de Tormes determinan por el contrario que los juicios mixtos se llevarían a cabo en la sinagoga, en domingo y con sol, esto es, de día.

Los juicios verificados en el corral de alcaldes o en la cámara serían definitivos y no se podía hacer apelación contra ellos.

En cuanto a la hora, se señalaba después de la misa matinal en la iglesia de la calongia, parroquial o del obispo, hasta que las campanas tañeren a tercia.

No podían celebrarse los juicios mixtos en sábados o en las fiestas judaicas"

"Fuero de Cuenca, cap. 29, leyes 16 y 30. Fuero de Ûbeda, \& 39 y 53, pp. 308 y 362 . Fuero de Béjar, \& $871,872,882$ y 887 , pp. 120 a 122 . Fuero de Zorita, \& 591, 592, 600, 604, pp. 274, 277 y 279. Fuero de Alba, \& 39, p. 308. Fuero de Coria, \& 219, p. 67. Fuero de Cáceres, 220, p. LVIII. Fuero de Salamanca, \& 259 y 341, pp. 170 y 202. Fuero de Ledesma, \& 176, 303, 390 y 400, pp. $247,268,284$ y 286. Fuero de Soria, \& 282, pp. 102-103. Fuero de Cuenca, cap. 29, leyes 16, 25 y 30. Fuero de Úbeda, tít. 39 y 53, pp. 308,362 y 363 . Fuero de Béjar, \& $855,871,872,882$ y 887 , pp. 118, 120-122. Fuero de Zorita, \& 591, 592, 599, 600,604, pp. 247, 268, 274, 277, 279, 284 у 286. Fuero de Alba, \& 39, p. 308. Fuero de Sepulveda, tit. 72, p. 90. 
En el juramento subsidiario se da la equiparación de las dos razas.

Por demandas de hasta cuatro mencales decían los fueros de Cuenca y sus análogos, que bastaba un simple juramento, y a partir de esa cantidad, debía jurar el cristiano sobre la cruz y el judío sobre la torá. En el fuero de Ledesma la cantidad límite se fija en medio mrs. El juramento no se efectuaría en el sábado ni en las pascuas judaicas ni debían jurar por San Juan Bautista. El fuero de Alba de Tormes también señala la cantidad de medio maravedí; rebasada la misma, si el cristiano no presentare carta y clérigo que hiciere jurar al judío, juraría éste sin carta $^{12}$.

\section{Logro}

Los fueros de la familia conquense consideran válidos y firmes los convenios entre cristianos y judíos, siempre que se efectuasen ante testigos; exceptúan los pactos sobre lucro, en los que la ganancia no podía aumentar más del doble, al cabo del año; después que se duplicase, ya no tendría logro la cantidad prestada. Al final del de Úbeda, fundándose en el fuero que tenían del rey don Fernando, entre cristianos y judíos, no darían estos a logro sino el tres por cuatro al cabo del año. En Coria el haber que todo judío diere a renuevo, produciría un maravedía la semana por un octavo de mrs.; y el sueldo, por un dinero; en el de Cáceres dice lo mismo pero a «sex» semanas.

En Alcaraz y Alarcón el que diere dineros por cebada o por pan en agosto, lograria diez dineros por cada mencal; el que más tomare, ya fuese cristiano, judio o moro, pagaría $10 \mathrm{mrs}$. al juez, a los alcaldes y al querelloso.

${ }^{12}$ Fuero de Cuenca, cap. 29, ley 17. Fuero de Úbeda, tit. 53, p. 362. Fuero de Bejar, \& 873, p. 120. Fuero de Zorita, \& 598, p. 277. Fuero de Ledesma, \& 393, p. 285. Fuero de Alba de Tormes, \& 39, p. 308. 
En Ledesma, el que diere su haber a judío para logro, tenía que darle su logro y su caudal. En el fuero de Alba, quien echare peños a judío ante testigos, no podía tomar más que una "pugesa» por el sólido.

Por último los judíos de Sepúlveda no podían dar a logro más de tanto y medio al año; si tomaban más y podía garantizarse con testigos, tenian que devolver el doble de la cantidad ${ }^{13}$.

\section{Oficios prohibidos}

En los fueros de Alcaraz y Alarcón se prohibía a los vecinos y a los judíos que fueran portadgueros ni merinos; en el fuero de Úbeda, los judios y moros no podían ser alcaides ni merinos ${ }^{14}$.

\section{Prendas}

Servian para garantizar el pago de una deuda o el cumplimiento de un contrato.

En los fueros se emplean indistintamente los vocablos peño y prenda, aunque peño más bien sirve para designar el objeto con relación al deudor, de donde derivó el verbo empeñar, y la prenda tenia su origen en el latín prendere, tomar, refiriéndose al acreedor.

La legislación sobre prendas es muy minuciosa en el fuero de Cuenca y sus homogéneos.

Se establecia una estricta reciprocidad de derechos entre cristianos y judios y la misma responsabilidad que tenía el juez se daba al albedín.

${ }^{13}$ Fuero de Cuenca, cap. 29, ley 20. Fuero de Zorita, \& 595, p. 276. Fuero de Úbeda, tít. 53, p. 362 y tít. 96, p. 406. Fuero de Coria, \& 294, p. 83. Fuero de Cáceres, \& 293, p. LXXII. Fuero de Alcaraz, Libro XII, 27, p. 525. Fuero de Alarcón, tít. 781, p. 525 . Fuero de Ledesma, \& 392, p. 285. Fuero de Alba, \& 392, p. 285. Fuero de Sepúlveda, tit. 72, p. 90.

${ }_{14}$ Fuero de Alcaraz, Libro 1, 20, p. 91. Fuero de Alarcón, tít. 16. Fuero de Úbeda, tit. 4, p. 257. 
Si se entregaba para responder de una obligación el doble de prendas, tenían que retirarlas en el plazo de 9 días o se perderian en su totalidad.

Cuando el albedín no hacía justicia, pagaría al juez 10 maravedís y el demandante quedaba en libertad para coger impunemente, en lugar de sus prendas, cualquier cosa que pudiese tomar de los judíos fuera de la alcacería; el mismo derecho tendría el judío contra el cristiano si el juez se negaba a darle satisfacción jurídica. Los demandantes podían acudir con un vecino de la otra ley a casa del incumplidor a tomar las prendas, las cuales guardaría dicho vecino con la prohibición de devolverlas a su dueño $\sin$ orden del querellante, y bajo multa de 10 maravedís; también se multaba al vecino que se negara a ir a prendar con hombre de distinta religión; si alguno se resistía a que le cogiesen las prendas o se las arrebataba a su contrario, intervendrían, según su caso, el juez o el albedín.

Después que los dineros fueren doblados, se podia vender la prenda, la cual debía estar durante tres días en manos del vendedor o del corredor; antes de retirar la prenda debía mostrar el deudor su dinero.

El que tuviera que atestiguar lo haría sobre el doble de las prendas o sobre su pie, según el fuero de Cuenca y derivados. Tanto el cristiano como el judío si ponian o metían el pie, y resultaban vencidos, el juez o en su caso el albedí, los metería en la cárcel del rey, de donde no saldrían hasta que pagaran.

Nadie podía prender a un judío ni a su bestia, en sábado ni durante sus pascuas.

Cuando un judío o un cristiano recibieran al de religión contraria por deudor de sus dineros, debían procurar que también se reconociesen como deudores su mujer y sus hijos, si los tuviesen, para que pudieran responder en caso de que el deudor muriese o huyere.

Los fueros de Coria y Cáceres determinan que los judíos no podían tomar peños sin que hubiera delante testigos, ni podian tomar prenda de hijo emparentado, bajo multa de 10 maravedís a los alcaldes y a los seis.

$\mathrm{Si}$ alguno conocía como suya alguna prenda que tuviere un 
judio, tenía éste que acreditar que lo había comprado a la luz del día - con sol-, y debía de dar otro, y si no pudiera confirmarlo, el cristiano podia apoderarse de la prenda jurando que era suya y que no la había vendido, dado ni empeñado. En los fueros de Alcaraz y Alarcón existe un precepto acerca de las cosas perdidas que se hallaran en poder de judíos; si no valian más de tres mencales, el dueño dando ese dinero, podía obtener su devolución; para prendas de más valor, tenía que presentar otor.

También el fuero de Ledesma obliga a los judios a tener de manifiesto los peños que le hubieran entregado a ganancia, y si alguien reconocía por suya alguna prenda, tenía la posibilidad de recuperarla, entregando la cantidad correspondiente.

Se establece en el fuero de Alba de Tormes que todo cristiano que tuviera alguna reclamación pendiente con un judio, podía ir a su casa acompañado de otro cristiano y tomarle una prenda y así haría a diario hasta que consiguiera resarcirse; podía acudir también al alcalde e incluso tomar en prenda al judío mismo hasta que obtuviera su derecho; se permitía la reciprocidad respecto al cristiano.

El judio que negase peños y se le reconocieran, los pagaria doblados a su dueño, y 6 maravedies al alcalde, además de perder las cantidades que hubiera dado. Los dineros sobre peños o fiadores, ganarían sólo hasta un año; a veces el judio ponía más cantidad de la prestada y en este caso, si el dueño de la prenda juraba sobre su cabeza, la cantidad verdadera y la pagaba, el judío tenía que devolverle su peño bajo la pena de aumentar un maravedi cada dia que lo retuviera la prenda ${ }^{15}$.

${ }^{15}$ Fuero de Cuenca, cap. 29. Fuero de Zorita, \& 578-597, 605, pp. 271-77 y 279. Fuero de Úbeda, tít. 53, pp. 361-363. Fuero de Coria, \& 295, 296, pp. 83, 84. Fuero de Cáceres, \& 294-295, pp. LXII-LXXIII. Fuero de Alcaraz, libro XIII, 2-14, 17, 20-23, pp. 557-565. Fuero de Alarcón, \& 566-573, 576-582, pp. 557-565. Fuero de Ledesma, \& 389, 393 y 397, pp. 284-286. Fuero de Alba de Tormes, \& 39-40, pp. 308-309. 
Estas relaciones carnales están muy penadas en los fueros.

Los de la familia conquense impone a la pareja hallada «faziendo nemiga e luxuria», el castigo de que ambos fuesen quemados.

En los fueros de Coria, Cáceres y Usagre, los alcaldes antes de juzgar este hecho tendrian que confirmarlo con dos cristianos y un judio, o viceversa, pero si presentaban la cristiana ante consejo, se haria la misma justicia con ella que con el judio.

El fuero de Sepúlveda diferencia la pena del judío de la de su cómplice, condenando al primero a ser despeñado, y a ella quemada; se haría antes pesquisas en caso de duda.

Respecto a los hijos que pudiera tener un cristiano con mujer de otra ley, hasta los tres años lo tendría la madre, y si el cristiano no lo reconocía por hijo y ganaba el pleito que por ello incoare, viviría siempre el niño a costa de la madre.

Si un joven se hiciera hereje, moro o judio, podia ser desheredado por sus padres.

En Sepúlveda llevaban el rigor hasta la cristiana que criase hijo de moro o de judío, o que morase con ellos; se consideraría mujer mala y sería hostigada y echada de la villa ${ }^{16}$.

\section{Tributos especiales}

Son muy variados.

En el fuero dado a la alberguería de Burgos se impone a los judíos de la ciudad que paguen al hospital diariamente, dos sólidos y un denario.

Los judios de Sahagún pertenecían al monasterio por donación de Alfons VII; en el fuero que concedió Alfonso el Sabio

${ }^{16}$ Fuero de Cuenca, cap. 11, ley 48. Fuero de Úbeda, tít. 29, ley 2, p. 304. Fuero de Alcaraz, 4, 49, p. 230. Fuero de Alarcón, tít. 256, p. 230. Fuero de Béjar, tit. 350, p. 55 . Fuero de Zorita, tit. 272, p. 155. Fuero de Coria, 135 , p. 48. Fuero de Cáceres, tít. 386, p. XC. Fuero de Usagre, \& 395. Fuero de Soria, \& 362 y 365 , pp. 137 y 139. Fuero de Sepúlveda, tít. 71, p. 90 y tít. 215 , p. 134. 
se ordena que los judios siguieran dando al abad los 18 dineros que acostumbraban a entregarle por razón del censo, además de los cien maravedis que pagaban anualmente, por yantar y por todo servicio.

En Ledesma, si pasaban por la villa el cadáver de un judío, tenían que dar 5 sólidos como portazgo; y todo el judio forastero que fuere a comprar a Ledesma, pagaria 2 dineros; 5 sólidos de portazgo tenía que dar también el judio que llevase mujer nueva a la villa, como esposa.

En cuanto a Sepúlveda, los judíos tenían que dar la pimienta por las fiestas de Navidad al concejo porque se les había concedido que se enterrasen dentro de los muros de la villa; si no cumplian el acuerdo, pagarian cien maravedís. También tenían que dar 13 mencales a los alcaldes dos veces al año porque no les tenian puertas por sus deudas y sus juicios ${ }^{17}$.

\section{Fuero de los judios de Haro}

En algunos fueros, al tratar de judíos se remite a los dados anteriormente a otras localidades. En el de Sahagún se hace referencia al que tenían los judíos de León en León, y posteriormente, se les asigna el fuero de los judios de Carrión. A los de Ledesma, se les da el fuero de los judíos de Ciudad Rodrigo; y a los judíos de Haro, se les concede como supletorio el que tenian los de Nájera. Ninguno de estos fueros aludidos nos es conocido en su totalidad.

Creo que el único fuero conservado, dedicado exclusivamente a judíos es el que otorgó Alfonso VIII a la aljama judía de Haro al mismo tiempo que le hacía donación del castillo; aunque no tiene fecha podemos señalarle el año 1187 que es cuando concede fuero a los otros habitantes de la ciudad.

Se conserva en el archivo de los duques de Frías, en confirmación original de Fernando IV del 6 de abril de 1304.

17 Fuero del hospital de Burgos, (2), p. 124. Fuero de Sahaguin, 41, p. 234. Fuero de Ledesma, \& 314 y 315, p. 271. Fuero de Sepulveda, tít. 72, p. 91. 
Además del castillo concede a los judios la heredad limitada por el camino que iba desde Haro a Bilibio hasta el Ebro y desde Briñas y Torrentejo hasta el pie de la fortaleza.

Las concesiones en el fuero son:

- Exención del pago de homicidio por los judíos que muriesen en accidente por agua, piedra, leña, por postema o por mano de médico mientras se curaba de heridas; tampoco debían pagar caloña cuando se encontraren algún cadáver fuera de las puertas del castillo; ni por golpear a cristiano si antes había sido maltratado el judío. Los cristianos que matasen a un judío o lo hiriesen o tomasen por los cabellos, si lo podían probar con dos testigos, cristiano y judío, pecharían 500 sólidos al rey, y si el querellante no tuviere testigos, podía salvarse el acusado con su jura y 12 vecinos.

- Exención de huéspedes: ni siquiera el señor podía hospedarse a la fuerza en casa de judio.

- Privilegio de inmunidad: castigando con la multa de 1.000 áureos al rey, al que lanzase contra el castillo piedras, dardos, lanzas o cualquier clase de armas. Si algún cristiano robara algo junto al castillo y fuere herido por manos de judio, no tendría que pechar nada por ello. El judio que tuviere que ser apresado, en vez de llevarlo a la cárcel, lo meterían en una casa especial destinada para este uso. Ningún judio podía ser condenado por el señor de la villa ni por ningún otro, por hurto o deuda, sino ante dos testigos, uno cristiano y otro judío.

- Exención de algunos tributos: No se podía prendar a los judíos que llevasen al castillo pan, vino, agua u otros alimentos. Ningún judío de Haro pagaría portazgo en todo el reino, ni podia ser prendado más que el deudor o fiador. Los judíos que comprasen bestias, ropa o alguna cosa mediante prenda y delante de dos testigos, no estaban obligados a dar otor.

- Autorización de convenios usuarios con cristianos, debiendo recibir capital y lucro según pacto, a cambio de grano o uva. - Juicios: cuando algún judio de Haro debiese jurar en juicio a un cristiano de fuera, o viceversa, juraría el cristiano en el lugar donde juraban los cristianos de Haro a los judíos, y el judío, en el lugar donde juraban éstos a los cristianos de Haro. 
Los judios podrían alzarse en juicio al alcalde de Haro y a las justicias del rey.

- Juramento: Por deuda de 5 sólidos para arriba, juraría el judio por oriente, y para abajo, por carta que leyese un clérigo que supiera hebreo.

- Aprovechamiento de bienes comunes: podían los judíos hacer uso de todas las aguas pertenecientes al rey, en las cuales podían pescar, hacer molinos y canales, lavar sus paños y hacer cualquier obra todos los días ${ }^{18}$.

\section{ÍNDICE DE LOS PRINCIPALES FUEROS QUE CONTIENEN DISPOSICIONES SOBRE JUDIOS. EDICIONES CONSULTADAS}

\section{Abia de las Torres (Palencia)}

Sólo queda noticia de un fuero que Alfonso VII, a ruego de su fidelísimo Rodrigo GómEz, otorga a Abia, en 1130.

Edición Justiniano Rodríguez Fernández, Palencia, panorámica foral de la provincia. Palencia 1981, pp. 87-90 y 234.

Alarcón (Cuenca)

Alfonso VIII le concedió el fuero de Cuenca en fecha incierta; probablemente a principios del siglo XIII; la versión romance es del último cuarto de ese siglo.

Edición: JEAN ROUDIL, Les fueros d'Alcaraz et d'Alarcón. Edition synoptique avec les variantes du Fuero d'Alcázar, introduction, notes et glossaire. Paris 1966.

\section{Alba de Tormes (Salamanca)}

No se conserva más que un manuscrito del final del xIII o principios del xIV, copia del privilegio de Alfonso X, dado en

18 Véase PIi ar Lfon Tu.Lo, «Nuevos documentos sobre la judería de Haro», en Sefarad XV, 1955, pp. 157-169. 
Sevilla el 11 de diciembre de 1279 , cofirmando el traslado de los fueros antiguos.

Edición: Américo Castro y Federico de Onis, Los fuetos leoneses, de Zamora, Salamanca, Ledesma y Alba de Tormes. Madrid 1916.

\section{Alcalá de Henares (Madrid)}

Es una colección de leyes otorgadas por los arzobispos de Toledo desde don Raimundo (1125-1150) hasta don Rodrigo Jiménez de Rada (1208-1247), en cuya época debió de traducirse. En algunas normas se consignan los nombres de los arzobispos que las habían concedido.

Edición: Galo SÁnchez, Fueros castellanos de Soria y Alcalá de Henares, Madrid 1919.

\section{Alcaraz (Albacete)}

En 1213 Alfonso VIII le concedió el fuero de Cuenca; su traducción al castellano la hizo Bartolomé de Uceda que acabó de redactarla el 23 de febrero de 1296.

Edición: JEAN ROUDIL, Les fueros d'Alcaraz et d'Alarcón. Edition synoptique avec les variantes du Fuero d'Alcázar, introduction, notes et glossaire. Paris 1966.

\section{Alcázar de San Juan (Ciudad Real)}

Parece que fue el maestre de la orden de San Juan, Rodrigo Pérez, el que dió a Alcázar el fuero de Cuenca en 1241; la traducción al romance se hizo durante el reinado de Sancho IV. JEAN ROUDIL señala las variantes de este fuero respecto al de Alcaraz, en la edición de este último.

\section{Béjar (Salamanca)}

El único ms. que se conserva es de la segunda mitad del siglo XIII, $y$ es un romanceamiento del fuero latino de Cuenca, aunque no contiene todas sus rúbricas. Fue dado por Alfonso VIII a fines del siglo XII. Alfonso X lo deroga tácitamente e impone 
el fuero real en 1261 , pero el mismo monarca se ve obligado en 1272 a restituir y confirmar su antiguo fuero.

Edición: Antonio Martín Lazaro, Fuero castellano de Béjar (siglo xIII). Preliminar, transcripción y notas. Madrid 1926.

\section{Belorado (Burgos)}

Alfonso I el Batallador da fuero a Belorado en agosto de 1116; después de la disolución de su matrimonio con doña Urraca en 1114 , gran parte de la provincia de Burgos quedó bajo el gobierno del rey aragonés.

Edición: Gonzalo Martínez Díez, Fueros locales en el territorio de la provincia de Burgos. Burgos 1982, pp. 134-135.

Briviesca (Burgos)

Fernando IV confirma en 1299 el fuero latino de Briviesca atribuido a Alfonso VII y fechado el 26 de diciembre de 1123. Es el primer fuero de Alfonso VII en territorio burgalés y en él aparecen casi todos los temas que se van a reproducir posteriormente en muchos otros fueros.

Edición: Gonzalo Martinez Diez, Fueros locales en el territorio de la provincia de Burgos. Burgos 1982, pp. 135-136.

\section{Burgos}

En 19 de marzo de 1103, Alfonso VI extiende el fuero de Burgos a 54 aldeas; en este diploma se hace una breve descripción del mismo, pero no se menciona a los judíos así como tampoco en privilegios concedidos después a los habitantes de Burgos por doña Berenguela y por Alfonso VII. En 1256, Alfonso el Sabio concede a Burgos el Fuero Real y nuevas mercedes; aparecen algunas normas referidas a judios en las respuestas legales que el último monarca mencionado contesta a demanda de los alcaldes burgaleses, el 6 de agosto de 1263 .

Edición: Gonzalo Martínez Dízz, Fueros locales en el territorio de la provincia de Burgos. Burgos 1982, pp. 211-212.

Burgos, alberguería u hospital del emperador. 
Fuero dado por Alfonso VI el 22 de febrero de 1085.

Edición: GONZAlo Martinez Diez, Fueros locales en el territorio de la provincia de Burgos, pp. 124-125.

\section{Cáceres}

Hay tres fueros latinos promulgados por Alfonso IX, uno de ellos dado en 23 de abril de 1229; fueron confirmados por Fernando III en 1231. Se conserva en un códice del siglo xIII del archivo municipal de la ciudad. Su precedente legislativo es el códice laurentino del fuero de Cuenca. En el ms. del archivo municipal se insertan también los fueros romanceados, pero en éstos es difícil determinar su número, fechas y monarcas otorgantes.

Edición: Pedro Lumbreras VAliente, Los fueros municipales de Cáceres. Su derecho público. Cáceres 1974.

\section{Libro de los fueros de Castilla}

Anónimo de la segunda mitad del siglo xiu que recoge el derecho territorial de su época en parte no fijado por escrito.

Edición: Galo SÁnchez, Libro de los fueros de Castilla. Barcelona 1924.

\section{Castrojeriz (Burgos)}

Es el primer fuero castellano conocido y el único de la época condal; fue dado por el conde Garci Fernández el 9 de marzo del 974; lo confirman su hijo el conde Sancho Garcés y otros monarcas posteriores hasta Alfonso VII, los cuales van añadiendo nuevos privilegios. Se conserva en confirmación de Fernando III del 3 de marzo de 1234.

Edición: MARTINEZ Diez, Fueros locales en el territorio de la provincia de Burgos, Burgos 1982, pp. 119-122.

\section{Catalifa}

Fuero dado por Alfonso VII en $114 \mathrm{I}$.

Edición: TomÁs MuÑoz Romero. Colección de Fueros Municipales y Cartas pueblas. Tomo I. Madrid 1847, pp. 532-533. 


\section{Córdoba}

En 3 de marzo de 1241 dió Fernando III a Córdoba el fuero de Toledo en su versión romance, y el 8 de abril del mismo año, la latina.

Edición: Miguel Ángel Ortí Belmonte, «Bol. Acad. de Córdoba», 70 (1954).

\section{Coria (Cáceres)}

Alfonso IX concede el fuero de Coria a los habitantes de Salvaleón en 1227, noviembre, 15. Guarda mucha analogia con el fuero de Castello-Bom, dado por el mismo monarca. Probablemente fue el mismo rey leonés el autor del fuero de Coria, y se puede situar entre los años 1208-1210. Sirvió de antecedente al de Cáceres, y a su derivado de Usagre.

Edición: El Fuero de Coria. Estudio jurídico por José MALDONADO y FERNÁNDEZ DEL TORCO. Transcripción y fijación del texto por Emilıo SAÉz. Madrid 1949.

\section{Cerezo de Rio Tirón (Burgos)}

En el fuero de esta población, dado por Alfonso VII en 1146, se cita a Villanova de judeos; no lejos de Villanueva, estaba Quintanilla de los judios nombrada solamente en la Estimación de los préstamos del obispado de Burgos, hecha en el siglo XIII y publicada por Flórez en la España Sagrada, tomo 26.

Edición: Gonzalo Martinez Diez, Fueros locales en el territorio de la provincia de Burgos. Burgos 1982, pp. 154-155.

\section{Cuenca}

Otorgado por Alfonso VIII a fines del año 1190, según se cree, el Forum Conche representa el momento cimero del derecho medieval castellano. Una gran familia de fueros se derivan del de Cuenca o están influidos por él, en adaptaciones latinas o romanceadas. Del texto latino hay dos ms. uno en el Escorial, de mediados del siglo xiII y otro en París, del xıv. Es un texto jurídico extenso que rompe la tradición de redactar cartas forales. En cuanto a los textos romances hay varias copias desde fina- 
les del siglo XIII, en las adaptaciones, como el de Alarcón, Alcázar, Béjar y Sabiote. Del fuero romanceado hay un ms. en el archivo municipal de Cuenca del siglo xIV, y otro del xv, en la Universidad de Valencia, pero existen ya adaptaciones del XIII.

Edición: UREÑa, Fuero de Cuenca (Formas primitiva y sistemática, texto latino, texto castellano y adaptación del fuero de Iznatoraf). Madrid? 1935. [No he podido consultar esta edición].

Valmaña Vicente, A.: Fuero de Cuenca, introducción y notas. Cuenca $2^{\text {a }}$ edic. 1978.

\section{Escalona (Toledo)}

Su fuero fue concedido el 4 de enero de 1130 por los hermanos Diego y Domingo Álvarez, señores de la villa. Sus preceptos sobre judios están tomados de la confirmación de los fueros de Toledo por Alfonso VII en 1118.

Edición: Alfonso Garcia Gallo, los fueros de Toledo, en AHDE XLV (1975), pp. 471-472.

\section{Haro (Logroño)}

Alfonso VIII concede a la aljama judía el castillo de Haro con fueros especiales; aunque no tiene fecha es probable que el privilegio se diera al mismo tiempo que el fuero a los otros habitantes de la ciudad, el 5 de mayo de 1187.

Se conserva en el archivo de los duques de Frías en confirmación original de Fernando IV de 1304.

Edición: PILAR León Tello, «Nuevos documentos sobre la judería de Haro", Sefarad XV (1955), pp. 157-164.

\section{Ledesma (Salamanca)}

El único ms. que se conserva de este fuero está en su archivo municipal, y fue redactado por los hombres buenos de la villa, probablemente a fines del siglo XIII. Recoge al principio la acotación del término y el breve fuero que le concedió Fernando II en 1111.

Edición: Américo Castro y Federico de Onís, Fueros Leo- 
neses de Zamora, Salamanca, Ledesma y Alba de Tormes, I. Madrid 1916.

\section{León}

Tiene varios fueros: los ordenados en las cortes celebradas en esta ciudad en el año 1020 por Alfonso V y la carta fechada el 31 de marzo de 1091 por la que Alfonso VI establece las normas por las que habian de regirse los pleitos y contiendas entre cristianos y judios.

Edición: Justiniano Rodriguez, Los fueros del reino de León, Tomo II. León 1981.

TOMÁs MuÑoz Romero, Colección de fueros municipales y cartas pueblas, Madrid 1847.

Lerma (Burgos)

Su fuero que data del 7 de mayo de 1148, se debe a Alfonso VII; se extiende a un amplio territorio que quedaba bajo la jurisdicción de Lerma. Se conserva en confirmación de Fernando IV, en el archivo municipal.

Edición: MARTínez Diez, Fueros locales en el territorio de la provincia de Burgos. Burgos 1982, pp. 152-153.

\section{Miranda de Ebro (Burgos)}

Hay un fuero de Alfonso VI en Burgos, enero de 1099, al cual se han añadido las confirmaciones de Alfonso VII, de Sancho III; más bien parece lo dio Alfonso VIII en 1177. En el archivo municipal de Miranda se conserva su confirmación por Fernando IV en 1298, la de Enrique III en 1393, Juan II, en 1425 y otras posteriores. Está basado en el fuero de Logroño.

Edición: Francisco Cantera Burgos, Fuero de Miranda de Ebro. Edición crítica, versión y estudio. Madrid 1945. Véase también G. Martínez Diez, op. cit., pp. 59-62 y 158-165.

\section{Molina de Aragón (Guadalajara)}

Le concedió fuero el conde Manrique de Lara en 1154 y fue adicionado por el infante don Alonso en 1240 y por doña Blan- 
ca, sen̂ora de Molina, en 1263 y 1272 . Alfonso XI otorgó otro fuero que no tiene fecha. Se halla copia en la Col. Burriel de la B.N.

Edición: SANCHo IzQuiERdo, El Fuero de Molina de Aragón, Madrid 1916.

\section{Nájera (Logroño)}

Alfonso VI concedió fuero a Nájera en 1076. Se reproducen los fueros que tenía la villa en tiempos de Sancho el Mayor y de don García. Es uno de los más importantes fueros del siglo XI. Se halla inserto en una confirmación original de 1304 .

Edición: Tomás Muñoz Romero, Colección de Fueros Municipales y Cartas pueblas. T. I. Madrid 1847, pp. 287-298.

\section{Pampliega (Burgos)}

Alfonso VIII en 31 de enero de 1209 extiende a Pampliega el fuero que Alfonso VII había concedido antes a Muñó. Se conserva en la confirmación que del mismo hicieron los R.C. en 1480 y que se inserta en el libro de Mercedes y Privilegios, leg. 314, fol. 17, del Archivo de Simancas.

Edición: Martínez Díez, Fueros locales en el territorio de la provincia de Burgos. Burgos 1982, pp. 181-183.

\section{Fuero Real}

Redactado con anterioridad a 1255; movido Alfonso el Sabio por su afán de unificar los derechos locales castellanos, fue concediéndolo como fuero municipal a distintas poblaciones como Sahagún, Soria, Burgos, Béjar y Madrid, pero estas ciudades prefirieron seguir con sus antiguos fueros y costumbres. Sus fuentes principales son el fuero de Soria y el Liber iudiciorum.

Edición: Los códigos españoles concordados y anotados. Vol. I. Madrid 1847.

\section{Pancorbo}

Por carta de Alfonso X expedida en Sevilla en 13 de mayo de 1263 , se observa que los judios tenían fuero común con los 
vecinos, pues pagaban conjuntamente los $400 \mathrm{mrs}$. de la martiniega, fonsadera, infurción y otros pechos. Véase Luciano Huidobro y Serna, «La judería de Pancorbo», Sefarad III (1943), fasc. I, pp. 155-166.

\section{Sahagún (León)}

La fecha de su fuero es el 25 de noviembre de 1085 y lo concede Alfonso VI a petición del abad don Bernardo. En 1152 Alfonso VII hizo donación de los judíos de la villa al monasterio de Sahagún, dándoles el fuero de los judíos de León. Un nuevo fuero dio el abad don Domingo a los que moraban en Sahagún, $\mathrm{y}$ Alfonso $\mathrm{X}$ en 1255 dio a la villa como fuero supletorio el Fuero Real.

Los fueros originales de Sahagún se conservan en la Academia de la Historia.

Edición: Tomas Muñz Romero, Colección de Fueros Municipales y Cartas Pueblas. Tomo I. Madrid 1847, pp. 301-320. Justiniano Rodriguez, Los fueros del reino de León. II, León 1981, pp. 227-238.

\section{Salamanca}

El concejo de Salamanca mandó hacer una extensa compilación de sus fueros, incluyendo sus antiguas leyes municipales y de derecho consuetudinario. Se conservan tres ms. medievales, dos en el Escorial y uno en el Archivo del Ayuntamiento de la ciudad; corresponden a finales del XIII y al XIV.

Edición: FEDERICO DE ONÍs, Los fueros leoneses de Zamora, Salamanca, Ledesma y Alba de Tormes. Madrid 1916.

Sepúlveda (Segovia)

Alfonso VI en 17 de noviembre de 1076 da fueros a Sepúlveda recogiendo los antiguos privilegios que tenía la villa del tiempo de su abuelo Alfonso V, de Fernán González y otros condes de Castilla. Ni en este fuero latino ni en una versión parcial romanceada que se dio en las cortes de Medina del Campo de 1305, se hace referencia a los judios. En 1300 se entrega al alcalde del 
rey por el concejo, el fuero con leyes originales y leyes adventicias. Presenta algunas coincidencias con el fuero de Cuenca, pero no es una adaptación del mismo. Fernando IV lo autorizó en 20 de junio de 1309.

Edición: Emilio SÁez, Los fueros de Sepúlveda. Segovia 1953.

\section{Soria}

El primitivo fuero de Soria no se conoce; debió de ser otorgado por Alfonso I el Batallador entre 1109 y 1114, al repoblar la ciudad. El Fuero extenso de Soria por Alfonso VIII, carece de fecha pero debió redactarse entre 1190 y 1214; probablemente, en 1195-96. El fuero de Soria sirvió de fuente al Fuero Real, que Alfonso X concedió a la misma ciudad en 1256. El Fuero de Soria atravesó por varios momentos en su redacción; la que ha llegado a nosotros refleja el derecho del siglo xIII. Se conservan del mismo dos códices del siglo xIv, uno en la Biblioteca Nacional y otro en el ayuntamiento de la ciudad, que está incompleto.

Edición: Galo SÁnchez, Fueros castellanos de Soria y Alcalá de Henares. Madrid 1919.

\section{Toledo}

Alfonso VI concedió fueros por separado a los castellanos, francos y mozárabes de Toledo; sólo se conserva este último, fechado el 19 de marzo de 1101. Alfonso VII reunió los tres fueros, confirmándolos y seguramente con adiciones, el 16 de noviembre de 1118; hay otra confirmación del privilegio de los mozárabes, del mismo monarca, fechada el 25 de marzo de 1155. Se conservan en el Archivo Municipal de la ciudad.

Edición: Alfonso García Gallo, Los fueros de Toledo, en AHDE, XLV (1975), pp. 341-488.

\section{Úbeda (Jaén)}

Su fuero es de la familia conquense, lo concedió Fernando III quien conquistó la ciudad en 1233. No se sabe la fecha exacta de la concesión del fuero. Se conserva copia en un ms. de la pri- 
mera mitad del siglo xIv en la Biblioteca Universitaria de Salamanca y otra del siglo xvi en el Archivo Municipal de la ciudad de Úbeda.

Edición: Mariano Peset, Juan Gutiérrez Cuadrado y José Trenchs Odena, Fuero de Úbeda. Valencia 1979.

\section{Usagre (Badajoz)}

Concedió fuero a Usagre el maestre de la orden de Santiago Pelay Correa, entre los años 1242 a 1275 . Es adaptación del Fuero de Cáceres. Se conserva en la sección de Códices del Archivo Histórico Nacional.

Edición: Rafael Ureña y Adolfo Bonilla, Fuero de Usagre anotado con las variantes del de Cáceres. Madrid 1907.

\section{Zorita de los Canes}

Su fuero deriva de las formas romanceadas del de Cuenca. Concedido por Fernando III, está sin fechar. Sólo se conserva en un códice de la Biblioteca Nacional, de fines del siglo XIII o principios del siguiente. Este fuero sustituyó en Zorita a la carta que le habia otorgado Alfonso VIII con el maestre de Calatrava Martín de Siones, en Pinilla, a 8 de abril 1180, que no se conoce más que por una transcripción romanceada inserta en la confirmación del mismo por Fernando III.

Edición: RAFAel de Ureña Smenjaud, El Fuero de Zorita de los Canes, según el códice 247 de la Biblioteca Nacional (s. XIII al XIV) y sus relaciones con el fuero latino de Cuenca y romanceado de Alcázar. Madrid 1911. 